\title{
Antimicrobial peptide-loaded liquid crystalline precursor bioadhesive system for the prevention of dental caries
}

This article was published in the following Dove Press journal: International Journal of Nanomedicine

\author{
Kelly Limi Aida' \\ Paula Fernanda Kreling \\ Karina Sampaio Caiaffa ${ }^{2}$ \\ Giovana Maria Fioramonti \\ Calixto $^{3}$ \\ Marlus Chorilli ${ }^{3}$ \\ Denise MP Spolidorio ${ }^{4}$ \\ Norival Alves Santos- \\ Filho ${ }^{5,6}$ \\ Eduardo Maffud Cilli ${ }^{5}$ \\ Cristiane Duque' \\ 'Department of Pediatric Dentistry \\ and Public Health, Araçatuba Dental \\ School, Sao Paulo State University \\ (UNESP), Araçatuba, São Paulo, \\ Brazil; ${ }^{2}$ Department of Endodontics, \\ Araçatuba Dental School, Sao Paulo \\ State University (UNESP), Araçatuba \\ São Paulo, Brazil; ; ${ }^{3}$ Department of \\ Drugs and Medicines, School of \\ Pharmaceutical Sciences, Sao Paulo \\ State University (UNESP), Araraquara, \\ São Paulo, Brazil; ' ${ }^{4}$ Department of \\ Physiology and Pathology, Araraquara \\ Dental School, Sao Paulo State \\ University (UNESP), Araraquara, \\ São Paulo, Brazil; ${ }^{5}$ Department \\ of Biochemistry and Chemical \\ Technology, Institute of Chemistry, \\ Sao Paulo State University (UNESP), \\ Araraquara, São Paulo, Brazil; \\ ${ }^{6}$ Registro Experimental Campus, \\ Sao Paulo State University (UNESP), \\ Registro, São Paulo, Brazil
}

Correspondence: Cristiane Duque Department of Pediatric Dentistry and Public Health, Araçatuba Dental School, Sao Paulo State University (UNESP), R. José Bonifácio, II93, CEP: I60I5-050 Araçatuba, São Paulo, Brazil

Tel +55 I8 363633I5

Email cristianeduque@yahoo.com.br
Background: Anticaries agents must interfere with the adhesion of Streptococcus mutans and its proliferation in dental biofilm, without causing host toxicity and bacterial resistance. Natural substances, including cationic antimicrobial peptides (CAMPs) and their fragments, such as $\beta$-defensin-3 peptide fragment (D1-23), have been widely studied. However, the chemical and physical stability of CAMPs may be compromised by external factors, such as temperature and $\mathrm{pH}$, reducing the period of antimicrobial activity.

Methods: To overcome the aforementioned disadvantage, this study developed and characterized a drug delivery system and evaluated the cytotoxicity and effect against $S$. mutans biofilm of a D1-23-loaded bioadhesive liquid crystalline system (LCS). LCS was composed of oleic acid, polyoxypropylene-(5)-polyoxyethylene-(20)-cetyl alcohol, Carbopol ${ }^{\circledR} 974 \mathrm{P}$ and Carbopol $^{\circledR}$ 971P. LCS was analyzed by polarized light microscopy (PLM), rheology (viscoelasticity and flow properties) and in vitro bioadhesion. The viability of epithelial cells was evaluated. Minimal inhibitory concentration (MIC) and minimal bactericidal concentration (MBC) against $S$. mutans were determined for D1-23 for further evaluation of the effect against $S$. mutans biofilm after 4 and $24 \mathrm{~h}$ of exposure to treatments.

Results: PLM, rheology, and in vitro bioadhesion tests showed that both viscosity and bioadhesion of LCS increased after it was diluted with artificial saliva. D1-23-loaded LCS system presented better activity against $S$. mutans biofilm after $24 \mathrm{~h}$ when compared to $4 \mathrm{~h}$ of treatment, showing a cumulative effect. Neither LCS nor D1-23-loaded LCS presented toxicity on human epithelial cells.

Conclusion: D1-23-loaded LCS is a promising drug delivery system for the prevention of dental caries.

Keywords: peptide fragments, drug delivery system, dental caries, biofilm, Streptococcus mutans

\section{Introduction}

Dental caries is the most common oral disease worldwide. The three main factors related to caries development had already been identified almost 100 years ago: diet, microbiota and susceptible tooth, influenced by sociocultural aspects and local risk factors such as salivary flow, teeth anatomy and oral hygiene. ${ }^{1}$ Nowadays, the caries ecology theory has hypothesized how the caries process occurs based on the succession of microorganisms in the dental biofilm determined by the frequency of sugar intake. Under severe and prolonged acidic conditions promoted by sugar metabolism, mutans streptococci and lactobacilli become dominant (aciduric stage) reducing drastically $\mathrm{pH}$ and leading to net mineral loss. ${ }^{2}$ Streptococcus mutans has been considered as the primary etiological agent of dental caries, due to its ability to metabolize a wide variety of carbohydrates and produce large amounts of acid, while also tolerating extreme concentrations of sugars 
and acids. ${ }^{3}$ Although dental biofilm is composed of multiple bacterial species, antimicrobial agents, which could interfere with the adhesion of $S$. mutans and its proliferation in dental biofilm, would be useful for controlling dental caries. ${ }^{4}$

Natural substances with antimicrobial properties have been studied as topical agents for oral cavity to reduce pathogens without causing bacterial resistance. ${ }^{4}$ Cationic antimicrobial peptides (CAMPs), such as $\beta$-defensins, have been introduced as future antimicrobial agents due to their rapid onset killing and broad-spectrum activity against Grampositive and Gram-negative bacteria, fungi and viruses, allied with potentially low levels of induced resistance. ${ }^{5}$

Human b-defensins (hBDs) are produced by epithelial cells in various organs, such as the eyes, skin, lungs, kidneys, pancreas and nasal and oral mucosa. In addition to their antimicrobial activity, $\beta$-defensins have an immunomodulatory function by modifying cell migration and maturation, inducing cytokines such as monocyte chemotactic protein-1, macrophage inflammatory protein-3 $\alpha$ (MIP-3 $\alpha$ ) and interferon- $\gamma$ inducible protein-10 (IP-10), enhancing chemotactic capacity and releasing histamine and prostaglandin A2. ${ }^{6-8} \mathrm{hBD}-3$ has shown action against the important primary and secondary colonizers of caries-related biofilm, such as S. mutans and Lactobacillus casei, with minimal inhibitory doses ranging from 1.25 to $200 \mu \mathrm{g} / \mathrm{mL} .{ }^{9}$ However, the large amino acid sequence ( 45 residues) and the presence of cysteine linkages on the structure make the synthesis of hBD-3 very expensive. In addition, native peptides tend to be easily degraded by external factors, such as temperature and $\mathrm{pH}$, with a reduced activity in the presence of salt, serum and proteinases. ${ }^{10}$ Therefore, modifications on the sequence or structure of natural peptides could generate a new synthetic CAMP that would have the same or superior broad-spectrum action against bacterial pathogens, low toxicity to the host and a minimal molecular size for low-cost production. ${ }^{11}$

Recently, fragments or analogs of CAMP have been synthesized, and their immunological and microbiological functions have been studied. Reynolds et al ${ }^{12}$ evaluated the bactericidal activity of peptide fragments of a $\beta$-defensin-3 derivative and found that the 23-amino acid N-terminal half (D1-23) of Defb14-1C $\mathrm{C}^{\mathrm{v}}$ (mouse ortholog of human $\beta$-defensin-3) is a potent antimicrobial, while the C-terminal half is not. To maintain chemical and physical stability and provide controlled release, drug delivery systems could be an attractive strategy for the administration of peptides. ${ }^{13}$

Several studies have evaluated the incorporation of peptides in drug delivery systems in the treatment of cardiovascular diseases, ${ }^{14}$ AIDS ${ }^{15}$ and diabetes. ${ }^{16}$ Liquid crystalline systems (LCSs) are a drug delivery system that can be used for incorporating peptides. ${ }^{17,18}$ LCS can promote controlled release of drugs and protect active ingredients from thermal degradation and photodegradation, while improving the effectiveness of these peptides. ${ }^{19}$ The bioadhesive property of these systems can maintain a high concentration of the peptide at the site of action for a long period, while also protecting it from environmental degradation. Therefore, the objective of this study was to characterize a liquid crystalline precursor bioadhesive system and evaluate the cytotoxicity and effect against $S$. mutans biofilm when incorporating D1-23 ( $\beta$-defensin-3 peptide fragment) in LCS.

\section{Materials and methods Preparation of the liquid crystal precursor bioadhesive system}

First, 2.5\% (w/w) Carbopol $^{\circledR} 974 \mathrm{P}$ (C974) and 2.5\% (w/w) Carbopol $^{\circledR}$ 971P (C971; Lubrizol, Wickliffe, OH, USA) were dispersed in water and homogenized at 2,000 rpm in a mechanical stirrer until complete dissolution, at room temperature $\left(25^{\circ} \mathrm{C} \pm 0.5^{\circ} \mathrm{C}\right)$. The $\mathrm{pH}$ of the binary polymeric dispersion was adjusted to 6.0 with triethanolamine (Synth; Diadema, Sao Paulo, Brazil) and manual agitation. ${ }^{20}$

Then, LCS (or F from formulation) was prepared weighing and mixing 40\% (w/w) polyoxypropylene-(5)polyoxyethylene-(20)-cetyl alcohol as the surfactant, $50 \%(\mathrm{w} / \mathrm{w})$ oleic acid as the oil phase and $10 \%(\mathrm{w} / \mathrm{w})$ binary polymeric dispersion containing $2.5 \%$ C974 and 2.5\% C971 as the aqueous phase at room temperature $\left(25^{\circ} \mathrm{C} \pm 0.5^{\circ} \mathrm{C}\right)$. Thus, the final polymeric concentration in the $\mathrm{F}$ was $0.25 \%(\mathrm{w} / \mathrm{w})$ for each polymer.

To evaluate the in situ lyotropic behavior, $F$ was diluted with artificial saliva in a $1: 10(\mathrm{w} / \mathrm{w})$ ratio to generate $\mathrm{F} 10$, a $1: 30(w / w)$ ratio to generate $F 30$, a 1:50 ratio to generate F50 and a 1:100 ratio to generate F100. A volume of $1 \mathrm{~L}$ of artificial saliva was prepared by mixing $8.0 \mathrm{~g}$ of $\mathrm{NaCl}, 0.19 \mathrm{~g}$ of $\mathrm{KH}_{2} \mathrm{PO}_{4}$ and $2.38 \mathrm{~g}$ of $\mathrm{Na}_{2} \mathrm{HPO}_{4}$. After complete mixing, the $\mathrm{pH}$ was measured as $6.8 .^{20}$

\section{Polarized light microscopy (PLM)}

A $10 \mu \mathrm{L}$ drop of F, F10, F30, F50 and F100 was applied on a glass slide and covered with a coverslip. Polarized light microscope (Jenamed; Carl Zeiss Meditec AG, Jena, Germany) at a magnification of $20 \times$ and at room temperature was used to analyze the glass slides to assess the presence of anisotropy or isotropy of the dispersion. ${ }^{21}$

\section{Rheological analysis}

A controlled-stress AR2000 rheometer (TA Instruments, New Castle, DE, USA) was used to analyze the rheological 
behavior of formulations in triplicate at $37^{\circ} \mathrm{C} \pm 0.1^{\circ} \mathrm{C}$. A parallel-plate geometry (40 $\mathrm{mm}$ diameter) and a sample gap of $200 \mu \mathrm{m}$ were used for F100, and a cone-plate geometry (40 mm diameter) and a sample gap of $52 \mu \mathrm{m}$ were used for $\mathrm{F}$. The formulations $(500 \mathrm{mg})$ were applied to the lower plate and maintained for 3 min prior to analysis. ${ }^{22}$ The same bath of formulations was used for each test.

\section{Determination of flow properties}

The determination of flow properties of formulations was performed using a controlled shear rate procedure ranging from 0.01 to $100 \mathrm{~s}^{-1}$ and back. Each stage lasted $120 \mathrm{~s}$ with an interval of $10 \mathrm{~s}$ between the curves. The quantitative analysis of flow behavior was determined using the following formula:

$$
\tau \mathrm{k} \cdot \gamma^{\eta}
$$

where $\tau$ is the shear stress, $\gamma$ is the shear rate, $\mathrm{k}$ is the consistency index and $\eta$ is the flow index. ${ }^{22}$

\section{Oscillatory analyses}

Viscoelastic region of the formulations was determined by means of a stress sweep in a constant frequency of $1 \mathrm{~Hz}$ over a stress range of $0.1-10 \mathrm{~Pa}$. A constant shear stress of $1 \mathrm{~Pa}$ was selected to perform the frequency sweep over a range of $0.1-10 \mathrm{~Hz}$. Thus, the storage $\left(\mathrm{G}^{\prime}\right)$ and loss $\left(\mathrm{G}^{\prime \prime}\right)$ modules were recorded using the following equation:

$$
\mathrm{G}^{\prime}=\mathrm{S} \cdot \omega^{\mathrm{n}}
$$

where $\mathrm{G}^{\prime}$ is the storage modulus, $\mathrm{S}$ is the formulation strength, $\omega$ is the oscillation frequency, and $n$ is the viscoelastic exponent. ${ }^{22}$

\section{In vitro bioadhesion strength}

This study protocol was performed according to the International Guideline Principles for Biomedical Research involving animals (Council for International Organization of Medical Sciences [CIOMS]/International Council for Laboratory Animal Science, 2012) and approved by The Animal Research Ethics Committee of the Araçatuba School of Dentistry, São Paulo State University (UNESP; protocol 2014/00618). Enamel blocks from sound bovine permanent incisors were cut transversally from the middle third of the buccal surface using a water-cooled, double-faced diamond disk (KG Sorensen, Barueri, Brazil). The specimens were then rounded using a high-speed, water-cooled cylindrical diamond bur (1095; KG Sorensen) and polished with wet 200-grit silicon carbide paper (T469-SF-Norton;
Saint-Gobain Abrasivos Ltda., Jundiaí, Brazil) to normalize the surface until it reaches the diameter of $1 \mathrm{~cm} .{ }^{18}$

The bioadhesive force between the bovine tooth block moistened with saliva, and the formulations were assessed using a TA-XTplus texture analyzer (Stable Micro Systems, Godalming, UK) in adhesion test mode (hold until time [HUT] mode). About $500 \mathrm{mg}$ of each formulation was packed in a small glass container with the flat surface. The teeth model was fastened to the upper movable probe, and the formulation sample was located on the lower platform. Before the test, the tooth was immersed in artificial saliva. The probe was lowered until it made contact with the sample, and it was kept in contact without any force for $60 \mathrm{~s}$. The probe was then raised at $0.5 \mathrm{~mm} / \mathrm{s}$, and the force needed for detachment was registered. Seven replicates of the same batch of formulations were analyzed at $37^{\circ} \mathrm{C} \pm 0.5^{\circ} \mathrm{C} .{ }^{18,22}$ The same enamel block was also used for all the tests to minimize the differences on the tooth surface's roughness. There were not enough remaining formulations on the tooth surface to be quantified.

\section{Antimicrobial agents}

\section{Preparation of peptide and chlorhexidine diacetate $(\mathrm{CHX})$}

D1-23-Defb 14-1C $\mathrm{C}^{\mathrm{v}}$ (D1-23) (sequence of amino acids from the peptide D1-23: FLPKTLRKFFARIRGGRAAVLNA) ${ }^{12}$ (molecular weight [MW]: 2603.88) was synthesized at the Institute of Chemistry (UNESP, Araraquara, Brazil). Solid-phase peptide synthesis was performed manually using Fmoc (9-fluorenylmethyloxycarbonyl) protocols on the Fmoc-Ala-Wang resin. ${ }^{23,24}$ The molecular masses of the peptides were determined using mass spectrometry, with a positive ion mode electrospray ionization apparatus (Bruker Optik GmbH, Ettlingen, Germany) in agreement with the corresponding calculated values. ${ }^{12}$ Purification of synthesized peptides was performed in a semi-preparative high performance liquid chromatography Beckman System Gold on a reverse phase $\mathrm{C} 18$ column $(2.1 \times 25 \mathrm{~cm})$. Final purity levels of peptides were determined at least $95 \%$ on a Shimadzu chromatography equipped with an analytical C18 reverse-phase column $(0.46 \times 25 \mathrm{~cm}) .{ }^{25}$ The positive control group was CHX, purchased from Sigma-Aldrich Co. ( $\mathrm{St}$ Louis, MO, USA). A stock solution of $2 \% \mathrm{CHX}$ was used for microbiological and cytotoxicity assays.

\section{Incorporation of antimicrobial agents into LCS}

Peptide fragment D1-23 and CHX were incorporated into the aqueous phase of formulation $(\mathrm{F})$ at the concentration of $1 \mathrm{mg} / \mathrm{mL}$ based on a previous study showing that about $4 \%$ of peptide is released from $\mathrm{LCS} .{ }^{26} \mathrm{CHX}$ is frequently used as an 
antimicrobial agent for oral application at $0.12 \%$ or $\sim 1 \mathrm{mg} / \mathrm{mL}$. Then, the groups of the study were D1-23 and CHX solutions, LCS (F), LCS containing D1-23 (F+D1-23) and LCS containing $\mathrm{CHX}(\mathrm{F}+\mathrm{CHX})$. LCS was diluted 10-fold before incorporating $\mathrm{CHX}$ and D1-23 to reduce the viscosity for biofilm assays. ${ }^{27}$

\section{Microbiological evaluation}

\section{Determination of minimal inhibitory concentration} (MIC) and minimal bactericidal concentration (MBC) MIC and MBC of D1-23 and CHX solutions were determined using the microdilution broth method, in 96-well microtiter plates, following the criteria previously described by Clinical and Laboratory Standard Institute (CLSI) ${ }^{28}$ Cell suspensions of S. mutans (UA159 - from University of Alabama, or ATCC $700610)$ at the mid-log phase $\left(\mathrm{OD}_{550}=0.5\right)$ were harvested by centrifugation (Hanil Combi centrifuge, 514R) for $10 \mathrm{~min}$, at 3,000×g; the supernatant was discarded, and the pellet was resuspended in $2 \times$ concentrated Mueller-Hinton broth (Difco Laboratories, Detroit, MI, USA) and diluted 1,000× in Mueller-Hinton broth. The final concentration of the suspension of $S$. mutans in the wells was $5-10 \times 10^{5}$ colony forming units/mL. Initially, the antimicrobial solution (peptide and $\mathrm{CHX}$ ) was serially diluted in sterile distilled water to obtain the concentrations ranging from 0.003 to $2 \mathrm{mg} / \mathrm{mL}$ and after $50 \mu \mathrm{L}$ microbial suspensions (correctly adjusted for the concentrations described earlier) were inoculated in each well. The plates were incubated at $37^{\circ} \mathrm{C}$ for $24 \mathrm{~h}$ in a $5 \% \mathrm{CO}_{2}$ atmosphere. Afterward, $15 \mu \mathrm{L}$ of $0.01 \%$ resazurin (SigmaAldrich Co.) was applied in each well and incubated for $4 \mathrm{~h}$ to promote an oxidation-reduction reaction and to determine cell viability by visually detecting any color change. The wells corresponding to MIC (the last blue well) and at least three previous wells were then homogenized, serially diluted and plated on Mueller-Hinton agar to determine the MBC. The plates were incubated at $37^{\circ} \mathrm{C}$ for $24 \mathrm{~h}$ in a $5 \% \mathrm{CO}_{2}$ atmosphere. The colonies were counted, and the number of viable bacteria was determined in colony forming units $/ \mathrm{mL}$. The MBC was considered when the peptide fragments killed (99\%) the tested microbial culture. CHX was used as a positive control. The negative control was the bacterial cultures without antimicrobial agents in Mueller-Hinton broth. All experiments were performed in duplicate in three independent days $(n=6)$.

\section{Biomass biofilm assays}

Briefly, $200 \mu \mathrm{L}$ of $5-10 \times 10^{5}$ cells of $S$. mutans (UA 159) in Brain Heart Infusion (Difco Laboratories) added 1\% sucrose was distributed per well in 96-well microtiter plates in triplicate and incubated at $37^{\circ} \mathrm{C}$ for $48 \mathrm{~h}$. After incubation, the wells were washed by immersion in $0.9 \%$ saline. Then, $150 \mu \mathrm{L}$ of each treatment (at $1 \mathrm{mg} / \mathrm{mL}$ ): D1-23 and CHX solutions, LCS (F), LCS containing D1-23 (F+D1-23) and LCS containing $\mathrm{CHX}(\mathrm{F}+\mathrm{CHX})$, was added and incubated for 4 and $24 \mathrm{~h}$ at $37^{\circ} \mathrm{C}$ and $5 \% \mathrm{CO}_{2}$. Negative controls were LCS without antimicrobial agents (F) and $0.9 \% \mathrm{NaCl}$ solution. After incubation, the plates were washed by immersion in distilled water three times to remove non-adhered cells. After a brief drying, $150 \mu \mathrm{L}$ of aqueous $1 \%$ crystalline violet was added to each well, and the plates were incubated at room temperature for $30 \mathrm{~min}$. Next, the crystalline violet solution was removed, and the plates were washed again three times. The plates were inverted on paper towels and remained for $2 \mathrm{~h}$ at room temperature to dry. The crystalline violet dye (stained biofilm) was then solubilized by incubation with $200 \mu \mathrm{L}$ of ethanol per well for $30 \mathrm{~min}$. Then, $100 \mu \mathrm{L}$ of the dye in ethanol was transferred to wells of a new microplate and submitted to reading in a spectrophotometer at $500 \mathrm{~nm}$ (Eon Microplates, Biotek Instruments, Winooski, VT, USA) to quantify the biomass of the biofilm. ${ }^{29}$ For the anti-biofilm assay, the mean absorbance values obtained from the control group (bacterial growth without antimicrobial agents) were calculated and considered as $100 \%$ of cell viability, and the percentage values of biofilm biomass reduction for the tested groups were calculated based on these criteria.

\section{Cytotoxicity assays}

These assays were conducted based on the methodology described by Bedran et $\mathrm{al}^{30}$ in duplicate, in three independent experiments $(n=6)$. Human epithelial cells forming the HaCat cell line (spontaneous immortalized non-tumorigenic human keratinocyte cell line - code 341; Banco de Células do Rio de Janeiro, Rio de Janeiro, Brazil) were grown in Dulbecco's Modified Eagle's Medium (DMEM; Thermo Fisher Scientific, Waltham, MA, USA) plus $10 \%$ fetal calf serum and $100 \mu \mathrm{g} / \mathrm{mL}$ of penicillin $\mathrm{G} /$ streptomycin until reaching a subconfluent density at $37^{\circ} \mathrm{C}$ in $5 \% \mathrm{CO}_{2}$ atmosphere. After that, the cells were treated with trypsin for 5 min (TrypLE ${ }^{\mathrm{TM}}$ Express; Thermo Fisher Scientific) at $37^{\circ} \mathrm{C}$, followed by the inactivation of proteases by adding $0.3 \mathrm{mg} / \mathrm{mL}$ of trypsin inhibitor. Cells were centrifuged ( $500 \times g$ for $5 \mathrm{~min}$ ), resuspended in DMEM and incubated in a $96-$ well microplate $\left(200 \mu \mathrm{L} /\right.$ well, $1 \times 10^{6}$ cells $\left./ \mathrm{mL}\right)$ overnight at $37^{\circ} \mathrm{C}$ in a $5 \% \mathrm{CO}_{2}$ atmosphere. After that, they were then stimulated with D1-23 and CHX solutions at concentrations of $0.001-1 \mathrm{mg} / \mathrm{mL}$ and $10 \mu \mathrm{L}$ of LCS containing or not containing D1-23 and $\mathrm{CHX}$ at $1 \mathrm{mg} / \mathrm{mL}(\mathrm{F}, \mathrm{F}+\mathrm{D} 1-23, \mathrm{~F}+\mathrm{CHX})$ for $24 \mathrm{~h}$ at $37^{\circ} \mathrm{C}$ in a $5 \% \mathrm{CO}_{2}$ atmosphere. Cell viability was determined by using a colorimetric 3-(4,5-diethylthiazol-2-yl)-2, 
5-diphenyltetrazolium bromide (MTT) cell viability assay (Sigma-Aldrich Co.) as the substrate at $5 \mathrm{mg} / \mathrm{mL}$. After $4 \mathrm{~h}$ of incubation, the culture medium with the MTT solution was replaced with $100 \mu \mathrm{L}$ of acidified isopropanol solution $(0.04$ $\mathrm{NHCl}$ ), an aliquot of each well was transferred to 96-well plates (Costar Corp., Cambridge, MA, USA) and the cell viability was measured using spectrophotometer (model 3550-UV; Bio-Rad Laboratories Inc., Hercules, CA, USA) at $570 \mathrm{~nm}$ wavelength. The mean was calculated and transformed into percentages, considering that negative control (DMEM) was defined as having $100 \%$ cell metabolism.

\section{Statistical analyses}

The characterization of the LCS was presented using descriptive analysis. Mean and SD for the bioadhesion strength values were determined for each group, and differences were analyzed using analysis of variance (ANOVA) and post hoc Tukey tests. Kruskal-Wallis and Mann-Whitney tests were applied to compare the percentage of biofilm biomass reduction for the groups, at different times. Data from cytotoxicity were submitted to ANOVA and post hoc Tukey or Student's $t$-tests to compare the effect of treatments on epithelial cells, considering each concentration separately. All tests were applied considering $p<0.05$.

\section{Results}

The results of photomicrographs of the formulations after adding $10 \%, 30 \%, 50 \%$ and $100 \%$ artificial saliva are shown in Figure 1. These photomicrographs demonstrate that the addition of saliva caused the isotropic systems to change in anisotropic systems. The addition of $30 \%$ saliva caused the "Maltese crosses" to appear, indicating the formation of a lamellar LCS. The hexagonal LCS formation occurred after the addition of $50 \%$ saliva based on the appearance of ribbed structures. The addition of $100 \%$ saliva to the formulation caused a change in an isotropic system, however, due to its high viscosity, indicated by a cubic LCS (F).

The flow and oscillatory characteristics of both $\mathrm{F}$ and F100 are shown in Figures 2 and 3, respectively. Figure 2 shows that $\mathrm{F}$ has a low viscosity, and when $100 \%$ saliva was added, F100 exhibited a high viscosity. In addition, it is also observed that F100 is potentially a thixotropic system, since the upward curve does not overlap the downward curve, indicating that F100 is more structured, because it needs a more time to return for its initial organization.

The frequency sweep test showed changes in the oscillatory properties of the formulations after adding 100\% saliva, because F100 presented $\mathrm{G}^{\prime}$ greater than F. Moreover, $\mathrm{G}^{\prime}$ of F100 is much larger than $G^{\prime \prime}$, indicating that the incorporation of saliva increased the rigidity of $\mathrm{F}$. Values of the bioadhesion test are presented in Table 1, indicating that the incorporation of $100 \%$ saliva into the F-system increased the bioadhesion strength and the work of bioadhesion on the surface of the bovine tooth five times larger than F.

Table 2 presents the values of MIC and MBC for the antimicrobial agent in solution, demonstrating that $\mathrm{CHX}$ was more effective in solution when compared to D1-23. Considering the biofilm assays, the percentage of $S$. mutans reduction in the biofilm after 4 and $24 \mathrm{~h}$ with the appropriated treatments is shown in Figure 4 . After $4 \mathrm{~h}$ of exposure, there was no statistical difference in the biofilm reduction comparing CHX and D1-23 incorporated in F and both agents in solution. After $24 \mathrm{~h}$, no difference was observed comparing $\mathrm{CHX}$ in solution or incorporated into $\mathrm{F}$, but higher
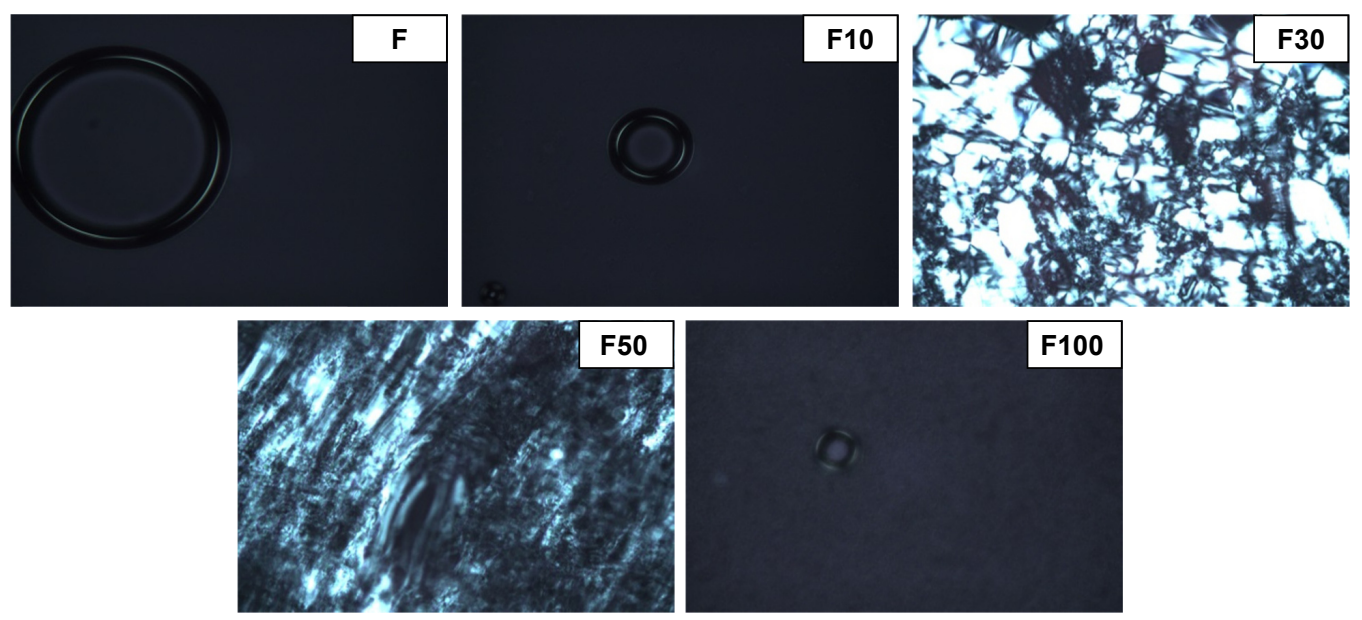

Figure I Photomicrographs representing the effect of artificial saliva in the structure of $\mathrm{F}$ (liquid crystal system) by light polarized microscopy at $20 \%$ magnification. Notes: $\mathrm{F}$ is the liquid crystal system; FIO is a $0.1: \mathrm{I}$ (wt/wt) dilution of $\mathrm{F}$ containing $10 \%$ artificial saliva; $\mathrm{F} 30$ is a $0.3: \mathrm{I}$ (wt/wt) dilution of $\mathrm{F}$ containing $30 \%$ artificial saliva; $\mathrm{F} 50$ is a $0.5: \mathrm{I}(\mathrm{wt} / \mathrm{wt}$ ) dilution of $\mathrm{F}$ containing $50 \%$ artificial saliva; and $\mathrm{FI} 00$ is a $1: 1$ (wt/wt) dilution of $\mathrm{F}$ containing $100 \%$ artificial saliva. 


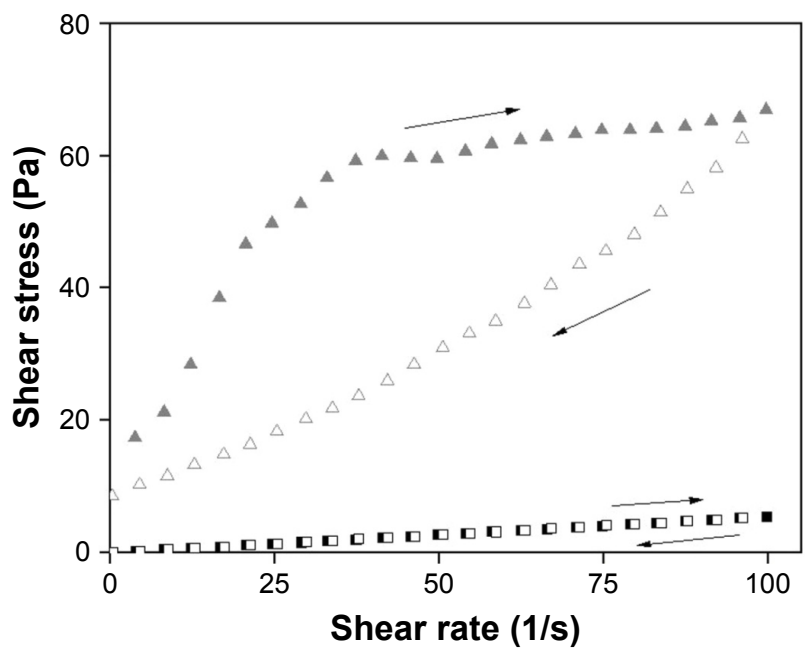

Figure 2 Rheograms of formulations F (squares) and FI00 (triangles).

Notes: Ascendant curve, filled symbols; descendent curve, empty symbols. $F$ is the liquid crystal system; FI00 is a I:I (wt/wt) dilution of F containing $100 \%$ artificial saliva.

biofilm reduction was noted for D1-23 in solution compared to D1-23 incorporated into F. Overall, biofilm reduction was higher in $24 \mathrm{~h}$ when compared to $4 \mathrm{~h}$, suggesting a cumulative effect of antimicrobial agents when incorporated into $\mathrm{F}$.

Figure 5 shows the cytotoxicity effects of the antimicrobial agents on epithelial cells. CHX and D1-23 solutions at $1 \mathrm{mg} / \mathrm{mL}$ were very cytotoxic, but when these agents were incorporated in $\mathrm{F}$ at $1 \mathrm{mg} / \mathrm{mL}$ concentration, cytotoxicity was not observed.

\section{Discussion}

This is the first in vitro study investigating the applicability of LCS containing an AMP fragment on tooth surfaces aimed to prevent dental caries. All these characterization results indicated that, in contact with the saliva, F (LCS) presents a more structured system, with greater viscosity and better bioadhesive

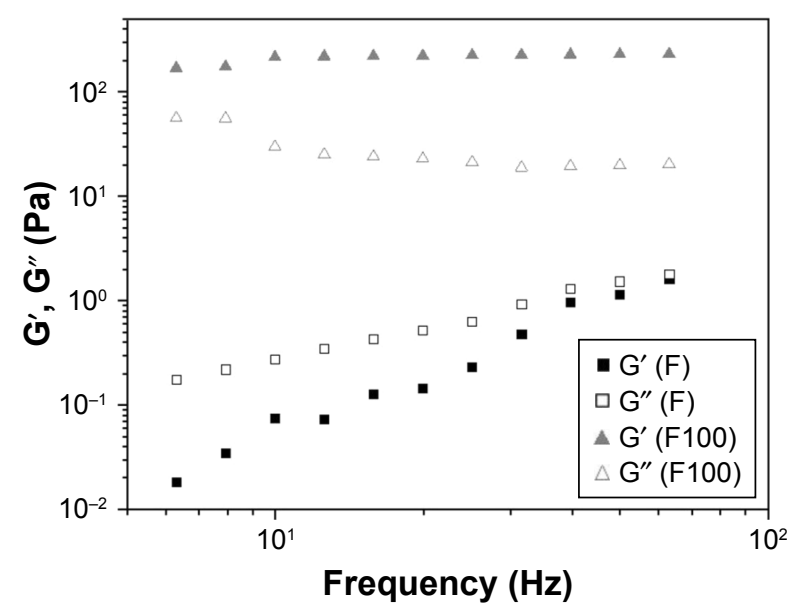

Figure 3 Variation of the storage module ( $G^{\prime}$, filled symbols) and loss module ( $G^{\prime \prime}$, empty symbols) as a function of the frequency to $\mathrm{F}$ and FI00.

Notes: $\mathrm{F}$ is the liquid crystal system; FI00 is a $\mathrm{I}: \mathrm{I}$ (wt/wt) dilution of F containing $100 \%$ artificial saliva.
Table I Results of in vitro bioadhesion strength in F and FI00

\begin{tabular}{lll}
\hline Formulations & $\begin{array}{l}\text { Peak of the } \\
\text { bioadhesive } \\
\text { strength }(\mathrm{mN})\end{array}$ & $\begin{array}{l}\text { Work of the } \\
\text { bioadhesive } \\
\text { strength }(\mathrm{mN} \cdot \mathbf{s})\end{array}$ \\
\hline $\mathrm{F}$ & $2.10 \pm 0.350^{\mathrm{a}}$ & $2.00 \pm 0.00 \mathrm{I}^{\mathrm{a}}$ \\
$\mathrm{Fl} 00$ & $11.00 \pm 1.200^{\mathrm{b}}$ & $11.5 \pm 0.500^{\mathrm{b}}$ \\
\hline
\end{tabular}

Notes: Values represent mean \pm SD. ${ }^{a, b}$ Different letters in the columns show statistical difference between the groups, according to ANOVA and Tukey tests $(p<0.05)$. $F$ is the liquid crystal system; FI00 is a I:I (wt/wt) dilution of F containing $100 \%$ artificial saliva.

Abbreviation: ANOVA, analysis of variance.

power on the tooth surface, which may increase the action of the peptide and improve the performance of the treatment.

Formulations composed of surfactant, an aqueous phase and an oil phase in different proportions can generate microemulsions, emulsions, liquid crystals or phase separation. ${ }^{31}$ The identification of the liquid crystalline phase is fundamental in the development of drug delivery systems, because the mesophase structure may influence drug release. This study observed that the addition of saliva, ie, the increase in the concentration of aqueous phase of system, caused isotropic systems to convert to anisotropic systems. The structures observed in the anisotropic field, such as streaks and Maltese crosses, are referred to as hexagonal and lamellar, respectively, whereas the microemulsions and cubic mesophases are isotropic and visualized as dark field. ${ }^{32}$ Maltese crosses starting to appear from the addition of $30 \%$ saliva indicate the formation of a lamellar LCS. The hexagonal LCS formation occurred after the addition of $50 \%$ saliva with the appearance of ribbed structures. The addition of $100 \%$ saliva in formulation caused a change to an isotropic system, indicated by a cubic LCS. The rigidity and high viscosity of the cubic phase retards diffusion and can provide a slow sustained release of the incorporated drug. ${ }^{33}$

The continuous rheological analysis is a widely used method for characterizing delivery systems, because it evaluates the facility that the material flows from a bottle, pumping a product in an industrial process, the spreading of a cream or lotion on skin and passage of product through the hole of a syringe. ${ }^{34}$ In the ascending curve, the flow behavior is classified into two types: Newtonian or non-Newtonian. The non-Newtonian flow can be further classified as pseudoplastic,

Table 2 MIC and MBC of DI-23 and CHX solution against planktonic S. mutans

\begin{tabular}{lll}
\hline $\begin{array}{l}\text { Antimicrobial } \\
\text { agents }\end{array}$ & MIC $(\mu \mathrm{g} / \mathrm{mL})$ & MBC $(\mu \mathrm{g} / \mathrm{mL})$ \\
\hline DI-23 & $15.60-31.25$ & $31.25-62.5$ \\
CHX & $0.30-0.60$ & $0.60-2.4$ \\
\hline
\end{tabular}

Note: DI-23, peptide DI-23.

Abbreviations: $\mathrm{CHX}$, chlorhexidine diacetate; $\mathrm{MBC}$, minimal bactericidal concentration; MIC, minimal inhibitory concentration; S. mutans, Streptococcus mutans. 


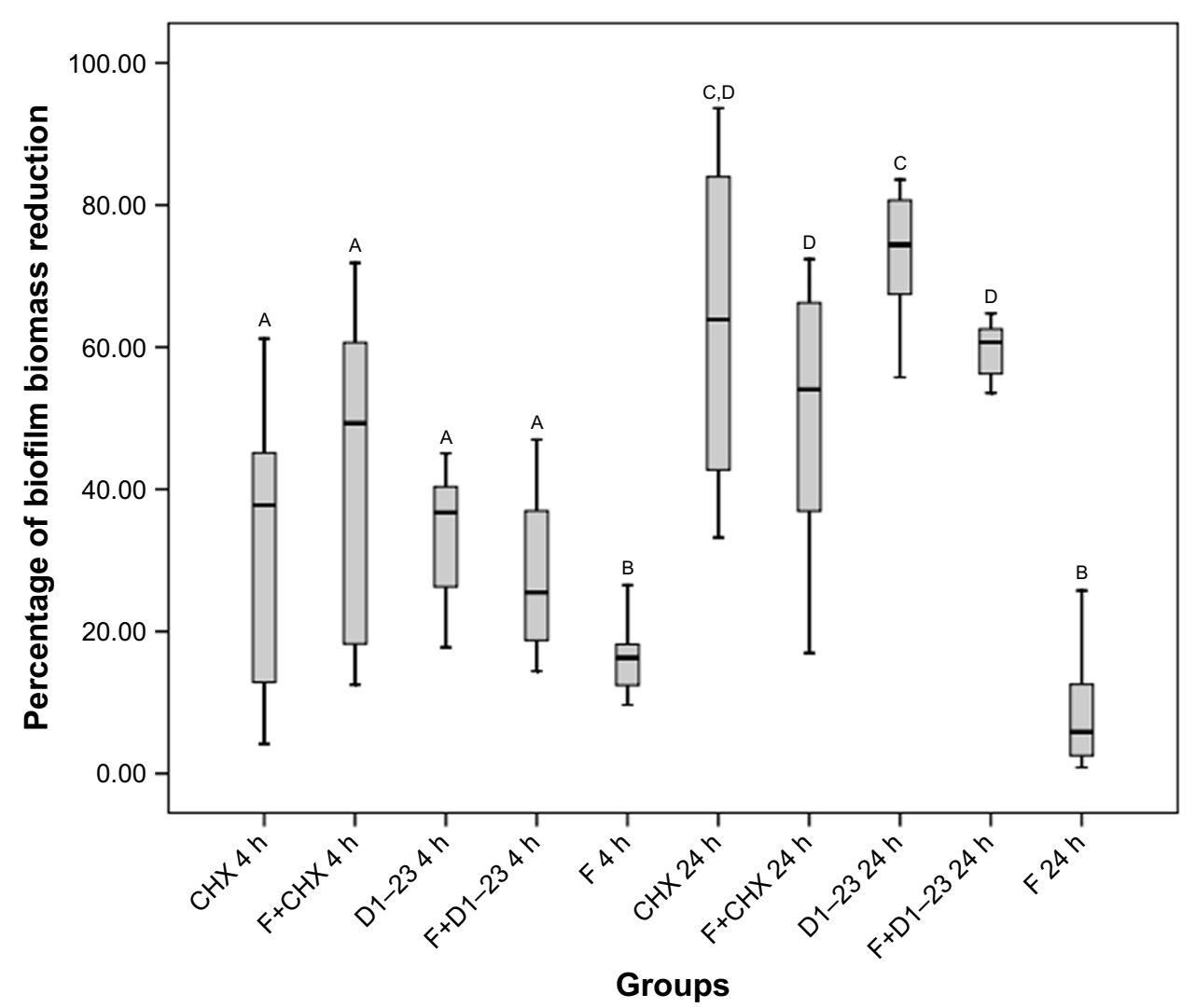

Figure 4 Boxplot of the percentage of biofilm biomass reduction after 4 and $24 \mathrm{~h}$ of the treatment.

Notes: Bars indicate minimum and maximum values. Boxes indicate lower and upper quartiles. Line in the middle of boxes is median. ${ }^{A-D}$ Different letters show statistical difference among the groups, according to Kruskal-Wallis/Mann-Whitney tests $(p<0.05)$. F, liquid crystalline formulation; DI-23, peptide DI-23; F+DI-23, formulation+peptide $\mathrm{DI}-23 ; \mathrm{F}+\mathrm{CHX}$, formulation+CHX.

Abbreviation: $\mathrm{CHX}$, chlorhexidine diacetate.

dilatant or plastic. In the descending curve, the materials are classified as thixotropic or reopetic. Flow is classified as Newtonian when the shear stress and rate are constant, or its viscosity is constant. ${ }^{35}$ The pseudoplastic flow occurs in materials that undergo a decrease in viscosity when the shear rate goes from low levels to higher levels. The increase in the shear rate guides rigid particles in the flow direction, creating shear thinning. ${ }^{36} \mathrm{~F}$ was determined to have a Newtonian flow and low viscosity. When $100 \%$ saliva was added to F, F100 exhibited a non-Newtonian pseudoplastic behavior $(\mathrm{n}<1)$

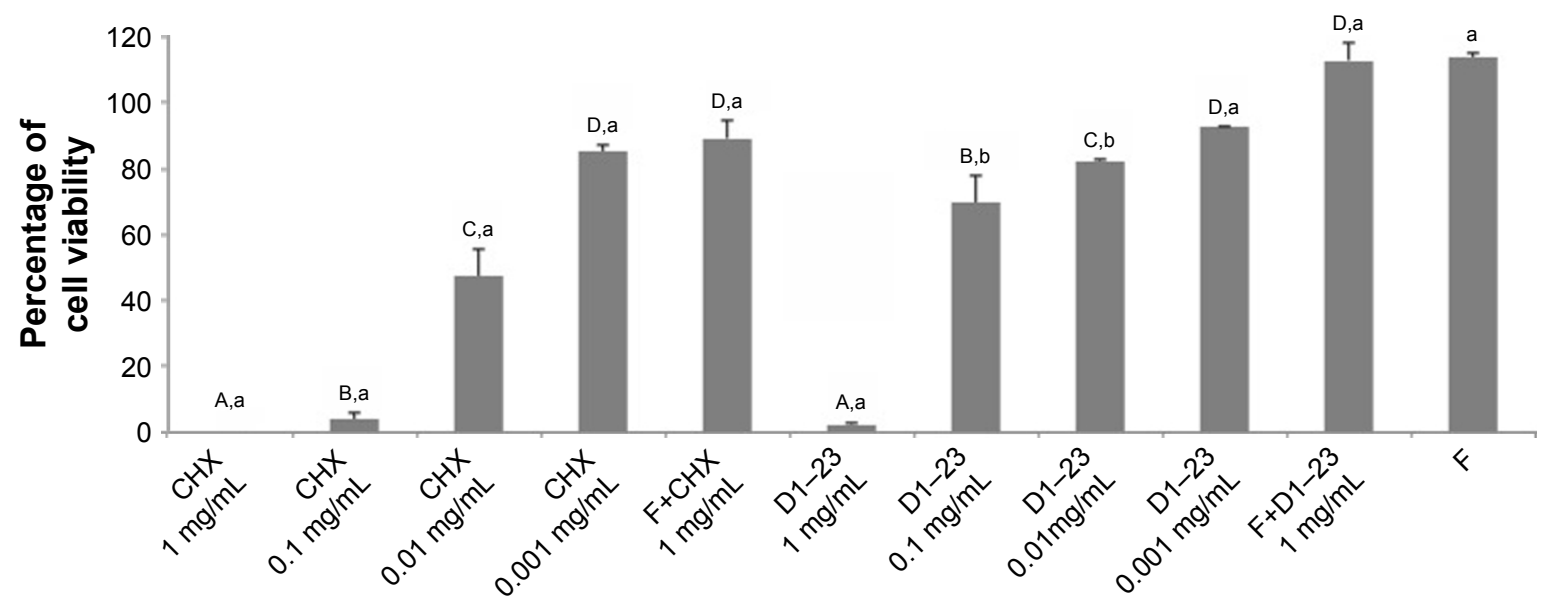

Figure 5 Mean (SD) of the percentage of epithelial cell viability after $24 \mathrm{~h}$ of the treatment.

Notes: ${ }^{A-D}$ Different uppercase letters show statistical difference among the concentrations of the same agent, according to ANOVA/Tukey tests $(p<0.05)$. ${ }^{a, b}$ Different lowercase letters show statistical difference among $\mathrm{CHX}$ and DI-23 or F+CHX and F+DI-23, according to Student's $t$-test ( $p<0.05$ ). F, liquid crystalline formulation. Abbreviations: ANOVA, analysis of variance; $\mathrm{CHX}$, chlorhexidine diacetate. 
and high viscosity. In addition, F100 was observed to have a thixotropic system, because the descending curve did not overlap the ascending curve, indicating that the system is more structured for F100 when compared to F.

The oscillatory analysis determined the viscoelastic properties of the formulations, providing information on the structural nature of the system, leading directly to the performance of the formulation. This information is obtained through the analysis of the elastic module $\left(\mathrm{G}^{\prime}\right)$ and viscous module $\left(\mathrm{G}^{\prime \prime \prime}\right)$ obtained in this assay. The elastic module, $\mathrm{G}^{\prime}$, is termed as the storage module, representing both the energy stored during deformation when the tension increases and the energy released when the tension is relaxed. The $G^{\prime \prime}$ viscous module is the viscous element that cannot store energy because the applied tension is dissipated in the form of irreversible deformation. ${ }^{37}$ In this current study, changes were observed in the oscillatory properties of the formulations after the addition of $100 \%$ saliva by using the frequency sweep test. Figure 3 plots the $\mathrm{G}^{\prime}$ storage module and the $\mathrm{G}^{\prime \prime}$ loss module versus frequency. The F organization degree increases when 100\% saliva was incorporated, the F100 value $\mathrm{G}^{\prime}$ module was higher than the F value $\mathrm{G}^{\prime}$ module. Furthermore, the F100 $\mathrm{G}^{\prime}$ storage module was greater than the $G^{\prime \prime}$ loss module, while the F value $\mathrm{G}^{\prime}$ module was less than the $\mathrm{G}^{\prime \prime}$ module, indicating that the saliva incorporation increased the rigidity of the system.

The addition of bioadhesive system in drug delivery was able to prolong the time of action of the drug, reducing the frequency of application of the product and thus increasing patient compliance to treatment. ${ }^{38}$ In our study, we observed that when $100 \%$ saliva was added, the formulation exhibited the best bioadhesive properties (Figure 3 ). This characteristic obtained from the formulation is due to the use of Carbopol as a bioadhesive agent. Carbopol is a bioadhesive polymer derived from the polyacrylic acid commonly used in bioadhesive pharmaceutical hydrogels, owing to their hydrophilic nature and reticulated structure, which makes them interesting for controlling drug release. ${ }^{22}$

The current study investigated the toxicity in epithelial cells and anti-biofilm activity against $S$. mutans of a CAMP fragment (D1-23) incorporated into a controlled drug delivery system, LCS (LCS or F in this study). AMP production is a major component of the innate immunity against infection that provides protection against bacteria, fungi, yeast and viruses. ${ }^{39}$ These molecules have been shown to be promising agents in controlling microbial growth due to their low concentration and selective antimicrobial activity, as well as low rates of antimicrobial resistance induction. ${ }^{40}$ S. mutans has been considered to be associated with dental caries ${ }^{41-43}$ based on their acid production and acid tolerance. ${ }^{3,44}$
The peptide fragment (D1-23) was chosen based on a prior study ${ }^{45}$ testing the antimicrobial activity of various peptide fragments, including defensins and cathelicidins. The D1-23 fragment showed the best results against $S$. mutans when compared to the other peptide fragments. In the current study, we determined MIC and MBC values for this peptide fragment, showing that this peptide has an antimicrobial activity against $S$. mutans with low values of MIC/MBC. Several studies have demonstrated the antimicrobial activity of defensins against $S$. mutans. ${ }^{46-48}$ Maisetta et al ${ }^{46}$ observed an $S$. mutans reduction of at least $3 \log 10$ after $1.5 \mathrm{~h}$ of incubation with $2 \mu \mathrm{g} / \mathrm{mL}$ hBD-3. Joly et $\mathrm{al}^{47}$ determined MIC values ranging from 3.4 to $5 \mu \mathrm{g} / \mathrm{mL}$ of hBD-3 against $S$. mutans strains. Nishimura et $\mathrm{al}^{48}$ found $\mathrm{MBC}<10 \mu \mathrm{g} / \mathrm{mL}$ of hBD-2 for several oral streptococci, including $S$. mutans. The mechanism of action of defensins against bacteria is through cell rupture and inhibition of lipopolysaccharide production. ${ }^{40}$ Lower MIC/MBC values were also observed for CHX in this current study. The cationic molecule of CHX is attracted toward negatively charged bacterial cell wall. This interaction is able to modify the integrity of cell membrane and allows $\mathrm{CHX}$ binding to phospholipids in the inner membrane, which leads to increased permeability and entrance of ions such as potassium and a progressive damage to the membrane by increasing the concentration of $\mathrm{CHX}^{49}$

Despite all the advantages that AMPs have demonstrated, including activity at low concentrations and activity across a wide spectrum, there are some limitations to their therapeutic application. One limitation is related to the high cationic activity of peptides. The inhibitory action of AMPs seems to be significantly reduced in biological fluids such as plasma, serum or saliva, ${ }^{40}$ while their chemical and physical stability may be compromised by external factors, requiring special attention to their efficacy and security. ${ }^{50}$ Therefore, LCS has been used to load peptides. LCS has been studied more intensively as a carrier of bioactive molecules in medicine, ${ }^{51}$ including applications for pulmonary drug delivery, ${ }^{52}$ diabetes treatment ${ }^{16}$ and even AIDS treatment. ${ }^{15}$ There are some reports in dentistry of using the drug delivery systems as the carrier of oral substances, with the majority of them being studied as an alternative for periodontal treatment. ${ }^{33,53}$ However, a few studies analyzed this specific system for oral application. Souza et $\mathrm{al}^{54}$ evaluated an LCS as a carrier for an antiseptic poly(hexamethylene biguanide) hydrochloride (PHMB). They observed that this system improved residence time and modulated drug release, indicating the use of this drug delivery system for PHMB.

With regard to cytotoxicity, the D1-23 and CHX solutions at $1 \mathrm{mg} / \mathrm{mL}$ were toxic for epithelial cells; however, 
both agents did not affect cell metabolism at low concentrations. D1-23 showed toxicity against two epithelial cell lines at concentrations $>0.2 \mathrm{mM}{ }^{45}$ In this study, even at high concentrations, when both antimicrobial agents were incorporated into LCS, they did not have a cytotoxic effect on epithelial cells. This occurs because LCS was not cytotoxic, and low concentrations of peptide and $\mathrm{CHX}$ are released from LCS. Any cytotoxic effect was observed when these LCSs were applied on macrophage cultures. ${ }^{55}$

Our main objective was to evaluate whether the LCS would work as a carrier, and if it could slowly release the antimicrobial agent and consequently have a cumulative effect. The current results indicate that the peptide fragment D1-23 in solution and in LCS reduced the $S$. mutans biofilm growth in both times of exposures (after 4 and $24 \mathrm{~h}$ ); however, we should emphasize that the concentration selected for the D1-23 and CHX solutions was $1 \mathrm{mg} / \mathrm{mL}$, regardless of the MBC. MIC/MBC assays of the tested agents showed that $\mathrm{CHX}$ had greater effect at lower concentrations when compared to D1-23. This means that the bactericidal concentration of CHX used in the biofilm assays was much higher than for D1-23. Even so, D1-23 presented similar results to $\mathrm{CHX}$ in both times of exposure. The concentration of both agents incorporated into LCS was also $1 \mathrm{mg} / \mathrm{mL}$. Data from literature report that the release of agents from this LCS is around $4 \%$ at $24 \mathrm{~h} .{ }^{26}$ Although data from the release of antimicrobial agents were not available in this current study, the peptide and CHX release from LCS was probably $>4 \%$, since the formulation was diluted before incorporation of antimicrobial agents for biofilm assays to reduce viscosity. Even so, D1-23 at $1 \mathrm{mg} / \mathrm{mL}$ into LCS presented similar antibiofilm activity to D1-23 in solution after $4 \mathrm{~h}$. D1-23 into LCS increased the residence time of the antimicrobial agent but did not potentiate the antimicrobial effect. We believe that the antimicrobial agents interact with the LCS promoting a cumulative effect of D1-23.

Other studies are necessary to confirm the effectiveness of LCSs for oral applications, perhaps using different methodologies promoting more time of contact between the antimicrobial agent and the site of action (tooth surface).

\section{Conclusion}

The current study developed and characterized an LCS with bioadhesive properties. Fragment of hBD-3, D1-23, incorporated in this LCS did not promote cytotoxic effect on epithelial cells. In solution, D1-23 had a similar effect on $S$. mutans biofilm compared to CHX, however, when this peptide was incorporated into LCS, promoted a cumulative antibiofilm effect, indicating that this drug delivery system might be a promising carrier to CAMP. This delivery system could be professionally used by dentists as a tool for biofilm control in patients with high risk to develop dental caries.

\section{Acknowledgments}

This study was funded by the Fundação de Amparo à Pesquisa do Estado de São Paulo (FAPESP; grants \#2012/19235-5, \#2013/12285-0,\#2013/07600-3 and \#2013/01565-1).

The authors would like to thank professors Robson Frederico Cunha and Sandra Maria Herondina Ávila de Aguiar for their contributions to this study.

\section{Disclosure}

The authors report no conflicts of interest in this work.

\section{References}

1. Fejerskov O. Concepts of dental caries and their consequences for understanding the disease. Community Dent Oral Epidemiol. 1997; 25(1):5-12.

2. Takahashi N, Nyvad B. The role of bacteria in the caries process: ecological perspectives. J Dent Res. 2011;90(3):294-303.

3. Hamada S, Slade HD. Biology, immunology, and cariogenicity of Streptococcus mutans. Microbiol Rev. 1980;44(2):331-384.

4. Freires IA, Rosalen PL. How natural product research has contributed to oral care products development? A critical view. Pharm Res. 2016; 33(6):1311-1317.

5. Gorr SU, Abdolhosseini M. Antimicrobial peptides and periodontal disease. J Clin Periodontol. 2011;38(Suppl 11):126-141.

6. Niyonsaba F, Ushio H, Nakano N, et al. Antimicrobial peptides human beta-defensins stimulate epidermal keratinocyte migration, proliferation and production of proinflammatory cytokines and chemokines. J Invest Dermatol. 2007;127(3):594-604.

7. Mccormick TS, Weinberg A. Epithelial cell-derived antimicrobial peptides are multifunctional agents that bridge innate and adaptive immunity. Periodontol 2000. 2010;54(1):195-206.

8. Wiesner J, Vilcinskas A. Antimicrobial peptides - the ancient arm of the human immune system. Virulence. 2010;1(5):440-464.

9. Ouhara K, Komatsuzawa H, Yamada S, et al. Susceptibilities of periodontopathogenic and cariogenic bacteria to antibacterial peptides, \{beta $\}$-defensins and LL37, produced by human epithelial cells. J Antimicrob Chemother. 2005;55(6):888-896.

10. Gordon YJ, Romanowski EG, McDermott AM. A review of antimicrobial peptides and their therapeutic potential as anti-infective drugs. Curr Eye Res. 2005;30(7):505-515.

11. Zhang L, Falla TJ. Host defense peptides for use as potential therapeutics. Curr Opin Investig Drugs. 2009;10(2):164-171.

12. Reynolds NL, De Cecco M, Taylor K, et al. Peptide fragments of a $\beta$-defensin derivative with potent bactericidal activity. Antimicrob Agents Chemother. 2010;54(5):1922-1929.

13. Bhardwaj V, Kumar MNVR. Fundamentals and applications of controlled release drug delivery advances. In: Siepmann J, Siegel RA, Rathbone MJ, editors. Delivery Science and Technology. New York: Springer; 2012:493-516.

14. Lestini BJ, Sagnella SM, Xu Z, et al. Surface modification of liposomes for selective cell targeting in cardiovascular drug delivery. J Control Release. 2002;78(1-3):235-247.

15. Avachat AM, Parpani SS. Formulation and development of bicontinuous nanostructured liquid crystalline particles of efavirenz. Colloids Surf B Biointerfaces. 2015;126:87-97. 
16. Okawara M, Hashimoto F, Todo $\mathrm{H}$, et al. Effect of liquid crystals with cyclodextrin on the bioavailability of a poorly water-soluble compound, diosgenin, after its oral administration to rats. Int J Pharm. 2014; 472(1-2):257-261.

17. Bernegossi J, Calixto GM, Sanches PR, et al. Peptide KSL-W-loaded mucoadhesive liquid crystalline vehicle as an alternative treatment for multispecies oral biofilm. Molecules. 2015;21(1):E37.

18. Calixto GM, Garcia MH, Cilli EM, Chiavacci LA, Chorilli M. Design and characterization of a novel p1025 peptide-loaded liquid crystalline system for the treatment of dental caries. Molecules. 2016;21(2):E158.

19. Guterres SS, Alves MP, Pohlmann AR. Polymeric nanoparticles, nanospheres and nanocapsules, for cutaneous application. Drug Target Insights. 2007;2:147-157.

20. Marques MRC, Loebenberg R, Almukainzi M. Simulated biological fluids with possible application in dissolution testing. Dissolution Technologies. 2011;8:15-28.

21. Salmazi R, Calixto G, Bernegossi J, Ramos MA, Bauab TM, Chorilli M. A curcumin-loaded liquid crystal precursor mucoadhesive system for the treatment of vaginal candidiasis. Int J Nanomedicine. 2015;10:4815-4824.

22. Calixto G, Yoshii AC, Rocha e Silva H, Stringhetti Ferreira Cury B, Chorilli M. Polyacrylic acid polymers hydrogels intended to topical drug delivery: preparation and characterization. Pharm Dev Technol. 2015;20(4):490-496.

23. Merrifield RB. Solid phase peptide synthesis. I. The synthesis of a tetrapeptide. J Am Chem Soc. 1963;85(14):2149-2154.

24. Kaiser E, Colescott RL, Bossinger CD, Cook PI. Color test for detection of free terminal amino groups in the solid phase synthesis of peptides. Anal Biochem. 1970;34(2):595-598.

25. Crusca E, Rezende AA, Marchetto R, et al. Influence of N-terminus modifications on the biological activity, membrane interaction, and secondary structure of the antimicrobial peptide Hylin-a1. Biopolymers. 2011;96(1):41-48.

26. Hu FQ, Hong Y, Yuan H. Preparation and characterization of solid lipid nanoparticles containing peptide. Int J Pharm. 2004;273(1-2):29-35.

27. Gawande PV, Leung KP, Madhyastha S. Antibiofilm and antimicrobial efficacy of DispersinB ${ }^{\circledR}$-KSL-W peptide-based wound gel against chronic wound infection associated bacteria. Curr Microbiol. 2014; 68(5):635-641.

28. CLSI-Clinical and Laboratory Standard Institute. Methods for Dilution Antimicrobial Susceptibility Tests for Bacteria That Grow Aerobically. 9th ed. Wayne, PA: CLSI Document; 2012:M7-M9.

29. Mattos-Graner RO, Napimoga MH, Fukushima K, Duncan MJ, Smith DJ. Comparative analysis of $\mathrm{Gtf}$ isozyme production and diversity in isolates of Streptococcus mutans with different biofilm growth phenotypes. J Clin Microbiol. 2004;42(10):4586-4592.

30. Bedran TB, Mayer MP, Spolidorio DP, Grenier D. Synergistic antiinflammatory activity of the antimicrobial peptides human betadefensin-3 (hBD-3) and cathelicidin (LL-37) in a three-dimensional co-culture model of gingival epithelial cells and fibroblasts. PLoS One. 2014;9(9):e106766.

31. Lawrence MJ, Rees DG. Microemulsions-based as novel drug delivery systems. Adv Drug Deliv Rev. 2000;45(1):89-121.

32. Calixto GMF. Desenvolvimento e caracterização de sistemas nanoestruturados bioadesivos contendo peptídeo análogo à adesina do Streptococcus mutans [Development and characterization of nanostructured bioadhesives containing peptide analogue to Streptococcus mutans adhesin; dissertation]. Araraquara, Brazil: São Paulo State University; 2013. Portuguese.

33. Shah JC, Sadhale Y, Chilukuri DM. Cubic phase gels as drug delivery systems. Adv Drug Deliv Rev. 2001;47(2-3):229-250.

34. Pestana KC. Microemulsões biocompatíveis de anfotericina b para administração oral. Estudo estrutural, liberação in vitro e farmacocinética pré-clínica [tesis]. Araraquara, Brazil: Sao Paulo State University; 2009.
35. Schramm G. Reologia e Reometria. Fundamentos Teóricos e Práticos [Rheology and Rheometry. Theoretical and Practical Fundamentals]. São Paulo, Brazil: Artliber; 2006. Portuguese.

36. Savic S, Lukic M, Jaksic I, Reichl S, Tamburic S, Müller-Goymann C. An alkyl polyglucoside-mixed emulsifier as stabilizer of emulsion systems: the influence of colloidal structure on emulsions skin hydration potential. J Colloid Interface Sci. 2011;358(1):182-191.

37. Pènzes $T$. Rheological analysis of the structural properties effecting the percutaneous absorption and stability in pharmaceutical organogels. Rheol Acta. 2004;43:457-463.

38. Smart JD, Riley RG, Tsibouklis J, et al. The retention of C-labelled poly(acrylic acids) on gastric and oesophageal mucosa: an in vitro study. Eur J Pharm Sci. 2003;20(1):89-90.

39. Pinheiro da Silva F, Machado MC. Antimicrobial peptides: clinical relevance and therapeutic implications. Peptides. 2012;36(2): 308-314.

40. da Silva BR, de Freitas VA, Nascimento-Neto LG, et al. Antimicrobial peptide control of pathogenic microorganisms of the oral cavity: a review of the literature. Peptides. 2012;36(2):315-321.

41. Tanzer JM, Livingston J, Thompson AM. The microbiology of primary dental caries in humans. J Dent Educ. 2001;65(10):1028-1037.

42. Gupta P, Gupta N, Pawar AP, Birajdar SS, Natt AS, Singh HP. Role of sugar and sugar substitutes in dental caries: a review. ISRN Dent. 2013; 2013:519421.

43. Nyvad B, Crielaard W, Mira A, Takahashi N, Beighton D. Dental caries from a molecular microbiological perspective. Caries Res. 2013;47(2): 89-102.

44. Becker MR, Paster BJ, Leys EJ, et al. Molecular analysis of bacterial species associated with childhood caries. J Clin Microbiol. 2002;40(3): 1001-1009.

45. Kreling PF, Aida KL, Massunari L, et al. Cytotoxicity and the effect of cationic peptide fragments against cariogenic bacteria under planktonic and biofilm conditions. Biofouling. 2016;32(9):995-1006.

46. Maisetta G, Batoni G, Esin S, et al. Activity of human $\beta$-defensin 3 alone or combined with other antimicrobial agents against oral bacteria. Antimicrob Agents Chemother. 2003;47(10):3349-3351.

47. Joly S, Maze C, McCray PB Jr, Guthmiller JM. Human $\beta$-defensin 2 and 3 demonstrate strain-selective activity against oral microorganisms. J Clin Microbiol. 2004;42(3):1024-1029.

48. Nishimura E, Eto A, Kato M, et al. Oral streptococci exhibit diverse susceptibility to human $\beta$-defensin -2 : antimicrobial effects of hBD-2 on oral streptococci. Curr Microbiol. 2004;48(2):85-87.

49. Prasanna SGV, Lakshamanan R. Characteristics, uses and side effect of chlorhexidine: a review. J Dent Med Sci. 2016;15(6):57-59.

50. Dailey LA, Wittmar M, Kissel T. The role of branched polyesters and their modifications in the development of modern drug delivery vehicles. J Control Release. 2005;101(1-3):137-149.

51. Chen Y, Ma P, Gui S. Cubic and hexagonal liquid crystals as drug delivery systems. Biomed Res Int. 2014;2014:815981.

52. Patil SS, Mahadik KR, Paradkar AR. Liquid crystalline phase as a probe for crystal engineering of lactose: carrier for pulmonary drug delivery. Eur J Pharm Sci. 2015;68:43-50.

53. Horev B, Klein MI, Hwang G, et al. pH-activated nanoparticles for controlled topical delivery of farnesol to disrupt oral biofilm virulence. ACS Nano. 2015;9(3):2390-2404.

54. Souza C, Watanabe E, Borgheti-Cardoso LN, de Abreu Fantini MC, Lara MG. Mucoadhesive system formed by liquid crystals for buccal administration of poly(hexamethylene biguanide) hydrochloride. J Pharm Sci. 2014;103(12):3914-3923.

55. Oliveira MB, Calixto G, Graminha M, Cerecetto H, González M, Chorilli M. Development, characterization, and in vitro biological performance of fluconazole-loaded microemulsions for the topical treatment of cutaneous leishmaniasis. Biomed Res Int. 2015;2015: 396894. 
International Journal of Nanomedicine

Dovepress

\section{Publish your work in this journal}

The International Journal of Nanomedicine is an international, peerreviewed journal focusing on the application of nanotechnology in diagnostics, therapeutics, and drug delivery systems throughou the biomedical field. This journal is indexed on PubMed Central, MedLine, CAS, SciSearch ${ }^{\circledR}$, Current Contents ${ }^{\circledR} /$ Clinical Medicine,
Journal Citation Reports/Science Edition, EMBase, Scopus and the Elsevier Bibliographic databases. The manuscript management system is completely online and includes a very quick and fair peer-review system, which is all easy to use. Visit http://www.dovepress.com/ testimonials.php to read real quotes from published authors.

Submit your manuscript here: http://www.dovepress.com/international-journal-of-nanomedicine-journal 